\title{
LOS TRES LIBROS ESPAÑOLES MÁS IMPORTANTES EN LA OFTALMOLOGÍA DEL S. XX
}

\author{
BARBÓN JJ ${ }^{1}$, ÁLVAREZ-SUÁREZ ML ${ }^{2}$, SAMPEDRO A ${ }^{1}$
}

La revista Archives of Ophthalmology publicó en el año 2001 una interesante relación en la que se enumeraban los 100 libros de oftalmología más importantes del s. XX. El trabajo también puede consultarse de forma más extensa, incluyendo algún comentario histórico y una breve reseña de cada libro, en la página web del Departamento de Oftalmología y Ciencias Visuales de la Universidad de Iowa (http:/webeye.ophth.uiowa.edu/dept/20thcenturybooks/100Books.htm). Aunque no deja de ser una apreciación subjetiva de los autores marcada por el idioma del libro, en la que primaría el inglés, y por su influencia específica en Norteamérica, la lista puede aproximarse bastante a una visión global sobre la literatura oftalmológica de la pasada centuria y al papel real desempeñado por la oftalmología española.

En esta lista aparecen tres libros escritos por compatriotas nuestros, La retina de los vertebrados de Ramon y Cajal, la Cirugía Ocular de Arru-

\section{1. $4 \mathrm{tat}$ : $: \mathrm{x}$ \\ CIRUGÍA OCULAR}
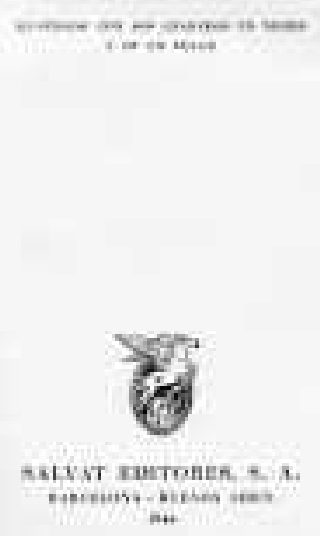

\footnotetext{
${ }^{1}$ Licenciado en Oftalmología. Hospital San Agustín de Avilés. Asturias. España. E-mail: jjbarbon@telecable.es

2 Doctor en Oftalmología. Hospital Álvarez-Buylla de Mieres. Asturias. España.
}

Dr. EAMSN CAITHCVIEIO

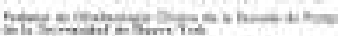

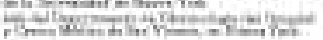

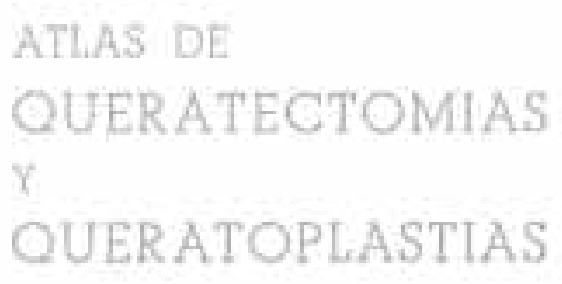

satvat moroers, s. h

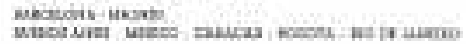


ga, y el Atlas de queratectomías y queratoplastias de Castroviejo. Cajal no era oftalmólogo pero este trabajo sobre la retina se incluye, a pesar de su publicación en la última década del s. XIX, por la gran influencia que tendrá en el desarrollo y conocimiento científico del ojo en el s. XX. Junto a Arruga y Castroviejo también son citados, en la breve descripción histórica que se hace sobre la Cirugía de Cataratas en la versión más extensa, Ignacio Barraquer (1884-1965) como inventor del erisifaco en 1917, que permitía la extracción del cristalino mediante una ventosa unida a una maquina de vacío regulable, y Joaquín Barraquer (1927), por la introducción, en 1957, de la alfaquimotripsina para la zonulolisis enzimática, lo que facilitaba enormemente la cirugía intracapsular.

El primero libro a considerar entre estas 100 obras fundamentales del s. XX sería La retina de los vertebrados de Santiago Ramón y Cajal. La obra de Cajal (Petilla de Aragón, Navarra, 1852Madrid, 1934) resulta tan inmensa y original que aún hoy es el autor más citado en libros y revistas de neurociencia. Sus descubrimientos fundamentales sobre el sistema nervioso y su estructura, donde podemos incluir a la retina, se basan en la Teoría Neuronal con la demostración histológica de su individualidad y su conexión por contigüidad, así como la ley de polarización dinámica para explicar la transmisión del impulso nervioso. La publicación, que se puede considerar una monografía por su extensión, apareció en 1893, en francés (La rétine des vertébrés), en la entonces importante revista belga La cellule, con 7 grandes láminas litografiadas que contenían más de 60 figuras. La traducción alemana (Die retina der wirbelthiere) apareció en 1894 llevada a cabo por Richard Greeff. Cajal ya había realizado estudios sobre la retina de aves (1888), reptiles y batracios (1891) y mamíferos (1891) y el presente trabajo representaba la culminación de sus descubrimientos sobre la estructura histológica y las conexiones celulares de la retina. En La retina de los vertebrados demuestra la unidad de la estructura retiniana en toda la escala biológica, la existencia en peces y mamíferos de conos y bastones, y la terminación libre de los mismos y de las neuronas retinianas, término acuñado por Waldeyer que el maestro utiliza aquí por primera vez en sus trabajos.

La Cirugía Ocular de Hermenegildo Arruga, ocupa otro de los puestos en la lista. El libro, edita- do en Barcelona por Salvat Editores en 1946, conoció 4 ediciones en español, 3 en francés y 2 en inglés (Ocular Surgery, McGraw-Hil,l New York), la primera en 1952, traducido por M.J. Hogan y L.E. Chaparro de la tercera edición española. A lo largo de casi 900 páginas Arruga (Barcelona, 18861972) hace un repaso exhaustivo de la cirugía palpebral, de las vías lagrimales, de la conjuntiva, cornea, esclera, iris, cristalino, del desprendimiento de retina, glaucoma, cirugía de músculos extraoculares, enucleación y exanteración, cirugía del vítreo, cirugía orbitaria y de la extracción de cuerpos extraños intraoculares. El tratado estaba profusamente ilustrado con 1099 imágenes en blanco y negro y 119 en color, la mayor parte grabados realizados por Alemany complementados con algunas fotografías. En el prólogo nos expresa su propósito de buscar que «esta obra no fuera exclusivamente la exposición de la cirugía que yo practico... he adoptado la norma de exponer, al lado de las técnicas que considero más ventajosas, las que hoy se practican por las personalidades más destacadas de la Cirugía oftalmológica mundial... facilitándoles [a mis colegas] así la ocasión de escoger las modalidades técnicas que mejor se acomoden a su manera de actuar». La obra fue por tanto una actualización quirúrgica de todos los tratados oftalmológicos publicados hasta entonces completada con las nuevas aportaciones aparecidas en monografías y revistas de la especialidad, todo ello bajo la inteligente mirada y la gran experiencia personal de Arruga. El libro mereció excelentes críticas por parte de toda la comunidad oftalmológica y fue una fuente de instrucción y aprendizaje para los oftalmólogos durante unos 20 años.

El tercer libro considerado entre los más destacados fue el Atlas de queratectomías y queratoplastias de Ramón Castoviejo, de 446 páginas, publicado por Salvat Editores en 1964, Ponencia Oficial del XL Congreso de la Sociedad HispanoAmericana y que será traducido al inglés (Atlas of keratectomy and keratoplasty, WB Saunders, Philadelphia, 1966), y también al francés y al alemán. Ramón Castroviejo Briones (Logroño, 1904Madrid, 1987) fue un publicador e investigador incansable a lo largo de toda su vida y en este libro, que se puede considerar su obra fundamental, recoge su experiencia personal de unas 3.000 queratectomías y 5.000 queratoplastias. La presentación en forma de Atlas, con 176 láminas y figuras (muchas realizadas también por Alemany) acompañadas por 
un escueto pero preciso texto explicativo, buscaba la presentación clara y práctica de las diferentes técnicas quirúrgicas, del instrumental, del tallado del trasplante o de las complicaciones y su tratamiento. El trasplante corneal fue el mayor campo de actuación de Castroviejo, contribuyendo como ningún otro oftalmólogo a su gran desarrollo actual. Entre sus muchas aportaciones cabe destacar que fue el primero en aplicar el trasplante al queratocono, actualmente la primera indicación de queratoplastia, un adelantado en el uso de queratectomías lamelares y queratoprótesis, y un incansable diseñador de instrumental quirúrgico con la creación de unos 200 prototipos a lo largo de su vida.

\section{BIBLIOGRAFÍA}

- Thompson HS, Blanchard DL. One hundred important 20th-century ophthalmic books. Arch Ophthalmol 2001; 119: 761-763.

- Cotallo de Cáceres JL, Hernández Benito E, Munoa Ruiz. $J L$, Leoz de la Fuente G. Historia de la Oftalmología Española. Madrid: LXIX Ponencia de la Sociedad Española de Oftalmología; 1993.

- Baratas Díaz LA. Significación histórica de La rétine des vertébrés de Santiago Ramón y Cajal: síntesis de su primera etapa investigadora. Asclepio, 1994; 46: 243-259.

- Vázquez Tapioles J. Trabajo.$^{\circ}$ 71: «La rétine des vertébrés». Volviendo por los fueros de Cajal. http://alojamientos.us.es/danatomia/srcajal025.htm

- Murube J, Muñoz Negrete F, Gutiérrez Carmona F. Ramón Castroviejo. Su herencia científica (parte 2). Studium Ophthalmologicum 2004; 22: 332-337. 